\title{
Retrieval of thin-ice thickness using the L-band polarization ratio measured by the helicopter-borne scatterometer HELISCAT
}

\author{
Stefan KERN, ${ }^{1}$ Martin GADE, ${ }^{1}$ Christian HAAS, ${ }^{2}$ Andreas PFAFFLING ${ }^{2}$ \\ ${ }^{1}$ Center for Marine and Atmospheric Research, Institute of Oceanography, Bundesstrasse 53, D-20146 Hamburg, Germany \\ E-mail: kern@ifm.zmaw.de \\ ${ }^{2}$ Alfred Wegener Institute for Polar and Marine Research, Bussestrasse 24, D-27570 Bremerhaven, Germany
}

\begin{abstract}
Climate warming makes an increasing thin-ice fraction likely to occur in the Arctic, underpinning the need for its regular observation. Synchronous helicopter-borne measurements of the sea-ice thickness and like-polarized L-band radar backscatter carried out along identical flight tracks north of Svalbard during winter are combined to develop an algorithm to estimate the thin-ice thickness solely from the L-band backscatter co-polarization ratio (LCPR). Airborne ice-thickness and LCPR data are smoothed along track (to reduce noise), co-located and compared. A linear and a logarithmic fit are applied using thickness values between 0.0 and $0.6 \mathrm{~m}$ and 0.0 and $1.0 \mathrm{~m}$, respectively. The thin-ice thickness is derived from the LCPR data using these fits, first for dependent data (used to obtain the fits) and subsequently for independent data. The results are compared to airborne ice-thickness measurements for ice-thickness values between 0.0 and $0.6 \mathrm{~m}$ using linear regression. The logarithmic fit gives the most reliable results, with a correlation of 0.72 and a rms difference of $8 \mathrm{~cm}$. It permits us to derive the thickness of thin ice (below $50-60 \mathrm{~cm}$ thickness) from airborne LCPR data with an uncertainty of about $10 \mathrm{~cm}$.
\end{abstract}

\section{INTRODUCTION}

Wintertime atmosphere-ocean energy exchange in icecovered regions is largest over leads and polynyas where open water and thin ice is abundant; it is particularly sensitive to the thickness of the thin ice. Numerical models predict a decrease of the summer Arctic ice extent due to a longer melt period (up to an almost complete loss), while it will remain nearly unchanged during winter (ACIA, 2004). Consequently, the seasonal ice cover can be expected to become thinner, and an increase of the thin-ice fraction is likely to occur in the near future. Sea-ice thickness observations were made with various methods (e.g. satellite altimetry, upwardlooking sonar (ULS) and in situ (e.g. Laxon and others, 2003; Rothrock and others, 2003; Haas, 2004; Kwok and others, 2004)). But except for in situ measurements, quantities such as the snow depth have to be assumed in order to obtain the ice thickness from the observed draft or freeboard, a major limitation (Kwok and others, 2004). Moreover, typical values of thin-ice draft (a few to about $25 \mathrm{~cm}$ ) or freeboard (a few millimetres to centimetres) lie within the error range of the used sensors. An alternative is to combine satellite observations with numerical models. This requires a high accuracy of model input data (e.g. air temperature), good availability and high quality of satellite data (e.g. fine spatial resolution) and the ability to unambiguously identify thin ice (e.g. Drucker and others, 2003). Another way is to use only remote-sensing data. Attempts to obtain the thin-ice thickness from airborne radar imagery have been made, for example, by Kwok and others (1995) and Wakabayashi and others (2004). They utilize a neural network trained with fully polarimetric data ( $\mathrm{L}$ - and C-band) and coincident infrared (IR) temperature observations, and a simple empirical relationship between ULS-observed ice thickness and the radar backscatter co-polarization ratio (CPR; L-band), respectively. Dierking and others (2003) mentioned that fully polarimetric data are indeed promising for thickness retrieval. However, although encouraging, these attempts reveal very different values for the maximum obtainable ice thickness: $10-100 \mathrm{~cm}$. In this paper, synchronous measurements carried out by two helicopter-borne sensors, an electromagnetic (EM) induction ice-thickness sounder (EMBird) and a multi-frequency, multi-polarization scatterometer (HELISCAT) are combined to form a unique dataset (section 3) to estimate the thin-ice thickness (section 4), similar to the approach of Wakabayashi and others (2004).

\section{BACKGROUND}

During the expedition ARK XIX/1 of the R/V Polarstern (28 February-24 April 2003; Schauer and Kattner, 2004), sea-ice and snow properties and distributions were observed north of Svalbard in situ and by helicopter-borne laser altimetry, video imagery, EM surveying and scatterometer measurements. On 19 April 2003, a tandem flight of EMBird and HELISCAT was carried out revealing a unique combination of data from both instruments. The synchronous flight was conducted using two helicopters, one towing the EM-Bird at $50 \mathrm{ft}(15 \mathrm{~m})$ height, immediately followed by the second one along the same track carrying the HELISCAT at $150-200 \mathrm{ft}(46-61 \mathrm{~m})$ altitude. Ice conditions were characterized by vast multi-year ice floes, intersected by regions of first-year ice. Thin and first-year ice formed in prominent, long and wide leads extending from the northwest towards the ice edge in the southeast, as a result of shear and divergence in the marginal ice zone.

The HELISCAT is a helicopter-based microwave scatterometer operating at frequencies of 1.0, 2.4, 5.3, 10.0 and 15.0 GHz ( $\mathrm{L}, \mathrm{S}, \mathrm{C}, \mathrm{X}$ and $\mathrm{K}_{\mathrm{u}}$ band, respectively). It permits measurement of radar backscatter quasi-simultaneously at the above frequencies at all like- and cross-polarizations from 50 to $150 \mathrm{~m}$ altitude. The HELISCAT uses a single broadband $96 \mathrm{~cm}$ parabolic dish antenna both for transmission and reception. The antenna is aft-looking and can be tilted during the flight from $23^{\circ}$ to $65^{\circ}$ nominal incidence 

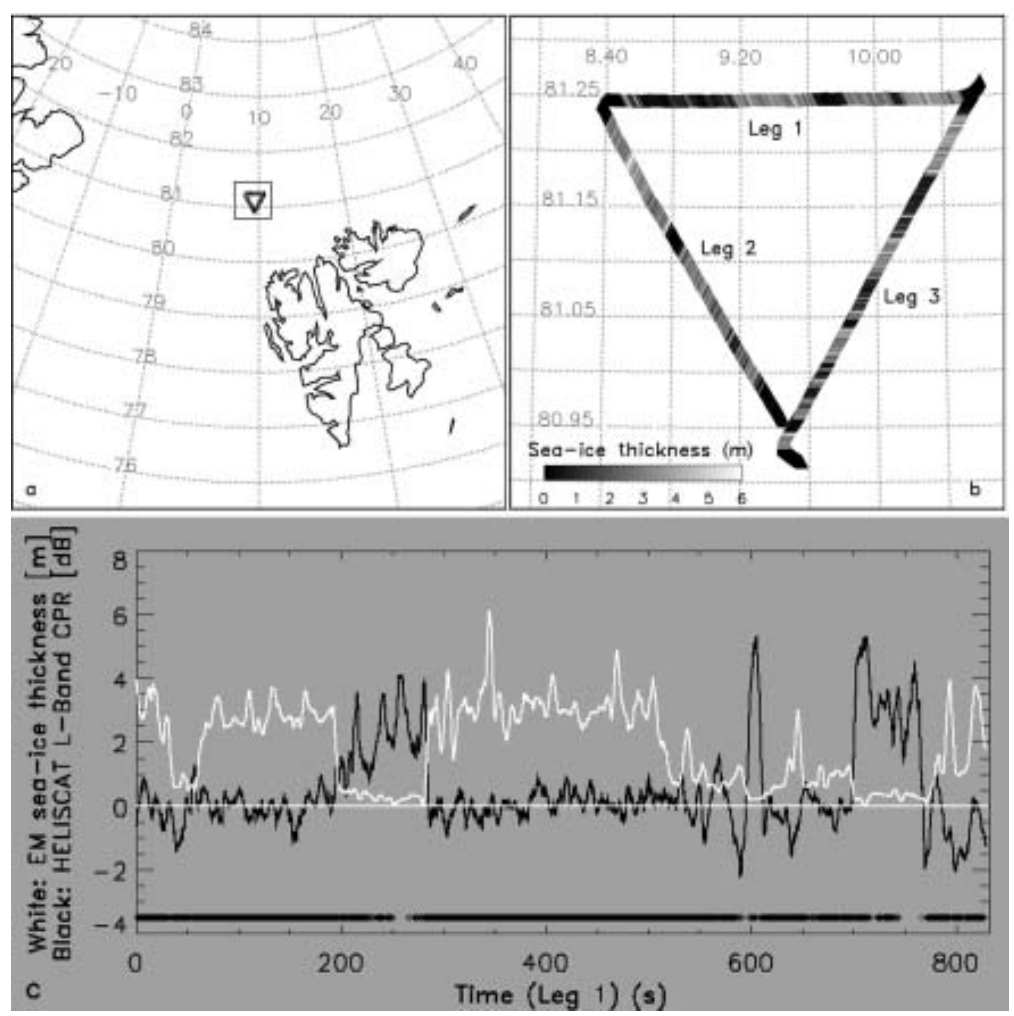

Fig. 1. (a) Location of the tandem flight carried out on 19 April 2003, north of Svalbard. (b) Zoom of the black box in (a) with the EM icethickness measurements. (c) EM ice thickness (white) and HELISCAT L-band CPR (black) for leg 1 (see (b)) (time $=0$ is upper right corner of triangle) averaged over $150 \mathrm{~m}$. Gaps in the line of diamonds at the bottom indicate that the SNR is $<20 \mathrm{~dB}$.

angle (Wismann and others, 1998). HELISCAT data are complemented by the helicopter's pitch and roll measured by a gyro, charge-coupled device (CCD) camera imagery of the antenna's footprint on the ground, the global positioning system (GPS) and hand-held digital photography. Data used in this paper were acquired at $65 \mathrm{~m}$ altitude at $40^{\circ}$ incidence angle, resulting in a footprint size at L-band of $20 \mathrm{~m} \times 27 \mathrm{~m}$ $( \pm 5-10 \mathrm{~m}$ due to variations in altitude and incidence angle during the flight). The average flight speed was $30-35 \mathrm{~m} \mathrm{~s}^{-1}$. The HELISCAT measurement time series of each frequency band were sampled at $10 \mathrm{kHz}$. Subsequently, Doppler spectra were calculated and the integral of the spectral Doppler peak was integrated within its $6 \mathrm{~dB}$ limits with a sample rate of $10 \mathrm{~Hz}$ (time-step of $0.1 \mathrm{~s}$ ). The instrumental noise was calculated from a part of the spectrum well off the Doppler peak with the same sample rate, and was used to obtain the signal-to-noise (SNR) ratio. This paper focuses on observations at L-band, because its long wavelength promises the largest penetration depth into thin ice and therefore a maximum obtainable thickness.

The EM-Bird is a purpose-built, small, lightweight sea-ice thickness profiler in operation since 2001 at the Alfred Wegener Institute, Bremerhaven. It is a $3.5 \mathrm{~m}$ long, $100 \mathrm{~kg}$ towed sensor suspended $20 \mathrm{~m}$ below a helicopter and operated at heights of $10-20 \mathrm{~m}$ above the ice surface. In short, the EM-Bird consists of an assembly of coils for the transmission and reception of low-frequency EM fields (3.69 and $112 \mathrm{kHz}$ ) and a laser altimeter. While the EM system is sensitive to the sensor's height above the conductive sea water, the sensor's altitude above the ice surface is determined with the laser altimeter. Over sea ice, the water surface coincides with the ice underside. Therefore, the difference of the height measurements of both components corresponds to the ice-plus-snow thickness. The method is calibrated over open water, where ice thickness is known to be zero. On a point-by-point basis, the estimates of the ice thickness agree within $\pm 0.1 \mathrm{~m}$ with drillhole data, whereas statistically determined level ice thickness can reach accuracies in the $\mathrm{cm}$ range (A. Pfaffling, C. Haas and J.E. Reid, unpublished information). However, due to the diffusive nature of the low-frequency EM induction field, its strength represents an average thickness of an area two to four times the instrument's altitude above the ice surface, i.e. an area of $30-80 \mathrm{~m}^{2}$ size. Due to this 'footprint', maximum ridge thickness can be underestimated by as much as $50 \%$ in the worst cases, depending on the geometry and consolidation of the ridge keel (Reid and others, 2006).

In order to reduce the scatter inherent in the data due to small-scale sea-ice heterogeneities and instrument noise, both time series are smoothed spatially along the flight track with a running mean. Different window widths (20, 50 and 100 data points, i.e. 65, 150 and $300 \mathrm{~m}$ ) are applied in order to investigate their effectiveness in removing outliers and scatter. In a further step, only those HELISCAT L-band CPR data are used where the SNR (smoothed with the same window) exceeds a threshold of 15 or $20 \mathrm{~dB}$.

Figure 1 shows the location of the measurements (Fig. 1a), the sea-ice thickness along the entire flight track measured by the EM-Bird (Fig. 1b) and in Figure 1c the seaice thickness along leg 1 (see Fig. 1b) together with the HELISCAT L-band co-polarization ratio (CPR, VV/HH polarized backscatter). Leg 1 crosses three multi-year ice floes separated by leads at 50 and 200-280 s flight time. Subsequently, a heterogeneous ice-cover is crossed, predominantly covered by thin and first-year ice. The CPR is around $0 \mathrm{~dB}$ over multi-year and first-year ice but takes 
values up to $5 \mathrm{~dB}$ over the thin ice. Like-polarized L-band radar backscatter (not shown) varied by up to $15 \mathrm{~dB}$ between thin and multi-year ice, which agrees with earlier observations (e.g. Rignot and Drinkwater, 1994).

\section{THIN-ICE THICKNESS ESTIMATION METHOD}

Radar backscatter measurements carried out in the laboratory over thin saline ice (e.g. Nghiem and others, 1997) reveal low like-polarization radar backscatter values which increase with thickness during initial growth above a threshold thickness of about $3 \mathrm{~cm}$ (by about $6-10 \mathrm{~dB}$ at L- and C-band). In order to observe such an increase under field conditions, the thin ice has to be tracked to ensure that an observed radar backscatter increase is caused by thin-ice growth and not by, for example, ice deformation. Onstott (1992) and Wakabayashi and others (2004) showed a CPR decrease with increasing thin-ice thickness, and that this decrease is more pronounced at large incidence angles, i.e. above $40^{\circ}$. This can be explained by changes in surface/ near-surface backscattering characteristics of thin saline ice during its growth, causing radar backscatter to increase. This backscatter increase is much larger at horizontal than at vertical polarization. Wakabayashi and others (2004) utilized this approach to estimate the thin-ice thickness. Our goal is to obtain a similar simple empirical relationship between EM ice thickness and HELISCAT L-band CPR data obtained simultaneously along the same flight track (Fig. 1c) to derive the thin-ice thickness solely from this CPR. For this purpose, both datasets are co-located using a crosscorrelation analysis and subsequently compared for different SNR thresholds and averaging windows.

Figure 2 shows a sample set of scatter plots of EM ice thickness vs HELISCAT L-band CPR for ice-thickness values between 0.0 and $1.0 \mathrm{~m}$ for leg 1 (see Fig. 1b). Two different SNR values (15 and $20 \mathrm{~dB}$ ) and three different averaging windows are realized. All images of Figure 2 indicate a constant CPR around $0 \mathrm{~dB}$ at ice-thickness values above about $0.6 \mathrm{~m}$ (dashed horizontal line) up to the maximum ice thickness (not shown), and a tail of increasing CPR toward zero ice thickness; this is similar to the findings of Onstott (1992) for C-band. Two different fits, a linear and a logarithmic one, are applied to obtain an empirical relationship between the two datasets, which allows calculation of the thin-ice thickness from the CPR data. The fits are applied to data with a CPR above zero minus one standard deviation of the average CPR $(\langle C P R\rangle)$ of thick ice $(>2.5 \mathrm{~m})$, calculated from EM ice-thickness measurements averaged over $300 \mathrm{~m}$ The EM ice-thickness measurement range is $0.0-0.6 \mathrm{~m}$ for the linear fit and 0.0-1.0 $\mathrm{m}$ for the logarithmic fit. The fits are plotted in Figure 2. Their equations are:

$D_{\mathrm{H}}=a_{0}+a_{1} \times \mathrm{CPR} \quad($ linear fit $)$

and

$D_{\mathrm{H}}=b_{0}+\frac{\left[\log \left(\mathrm{CPR} \times b_{1}+0.02\right)+|\log (0.02)|\right] \times\left(-b_{0}\right)}{|\log (0.02)|+\left|\log b_{2}\right|}$

(logarithmic fit);

CPR is the HELISCAT L-band CPR data, $D_{\mathrm{H}}$ is the HELISCATderived ice thickness, $a_{0}=0.503$ and $a_{1}=-0.067$ are the intercept and slope of the linear fit and $b_{0}=1.0, b_{1}=0.7$ and $b_{2}=$ maximum CPR value are the coefficients of the logarithmic fit. The larger CPR and thickness range used to establish the logarithmic fit was taken to ensure a realistic continuation of the fit for an ice thickness around the selected maximum value of $0.6 \mathrm{~m}$

A larger SNR threshold $(20 \mathrm{~dB}$ instead of $15 \mathrm{~dB})$ significantly reduces the number of outliers (circles in Fig. 2a and $b$ ). Their number is also determined by the width of the averaging window: 150, 65 and $300 \mathrm{~m}$, in Figure 2a, c and d, respectively. Both have an influence on the quality of the fit. This is indicated by different rms differences between the measured ice thickness and the one estimated using one of the fits (see numbers in the upper right of Fig. 2a-d). These differences as well as the HELISCAT-derived ice thickness (section 4) are obtained using only data where the measured (EM) ice thickness is between 0.0 and $0.6 \mathrm{~m}$ and CPR values are larger than zero plus one standard deviation of $\langle C P R\rangle$ (see above). We decided to rely on CPR data with a SNR above $20 \mathrm{~dB}$ and to use an averaging window of $150 \mathrm{~m}$. Although the rms difference using this averaging window is slightly larger compared to using a window of $300 \mathrm{~m}$ (see Fig. 2a and d), a window of $150 \mathrm{~m}$ allows us to resolve thin-ice areas, which extend over 100-200 m along the flight track, and to keep the entire thickness range starting right from $0 \mathrm{~cm}$.

\section{RESULTS}

Figure 3 shows the thin-ice thickness estimated from HELISCAT L-band CPR data $(S N R>20 \mathrm{~dB})$ using the linear (Fig. 3a and c) and the logarithmic (Fig. $3 \mathrm{~b}$ and d) fit obtained from the data of leg 1 (150 m average; see Fig. 2a). Figure 3a and $b$ show the results of the thickness estimation for leg 1 , i.e. using dependent data. Figure $3 \mathrm{c}$ and d show the results of this estimation for leg 3, i.e. using independent data. Figure 3 reveals that the logarithmic fit yields lower ice-thickness values than the linear fit. Table 1 summarizes the results of a regression analysis of HELISCAT-derived and EM thin-ice thickness, together with the correlation between both datasets (assuming a linear relationship) and the standard deviation of the mean thin-ice thickness in the range 0.0$0.6 \mathrm{~m}$. These results are given separately for the dependent data of leg 1 (see Fig. $3 a$ and b) in the first data line, and for the independent data of leg 3 (see Fig. 3c and d) in the second data line. The two bottom lines in Table 1 show a comparison between mean results of regression analyses between HELISCAT-derived and EM thin-ice thickness of all legs for two different averaging windows (150 and $300 \mathrm{~m}$ ). It should be noted that, in case of using an averaging window of $300 \mathrm{~m}$, the HELISCAT-derived thickness is derived from the fits plotted in Figure $2 d$ instead of those given in Figure 2a.

\section{DISCUSSION}

For the ice thickness and CPR used in this study (see sections 2 and 3), HELISCAT-derived and EM thin-ice thickness are in reasonable agreement with each other within the uncertainties given by the two involved sensors: about $\pm 0.05 \mathrm{~m}$ for EM measurements averaged over a reasonable number of single measurements, and $\pm 0.14 \mathrm{~m}$ for the CPR (see section 2 and Fig. 2). In detail, correlations are similar for the linear $(0.724)$ and the logarithmic fit (0.723). The rms difference of the regression (for thickness values of $0.0-0.6 \mathrm{~m}$ ) between HELISCAT-derived and EM thin-ice thickness is similar for both fits, while the intercept of the regression line is substantially higher for the linear fit: $0.17 \mathrm{~m}$ compared to $0.06 \mathrm{~m}$ The standard deviation of the mean HELISCAT-derived ice thickness is in closer agreement 

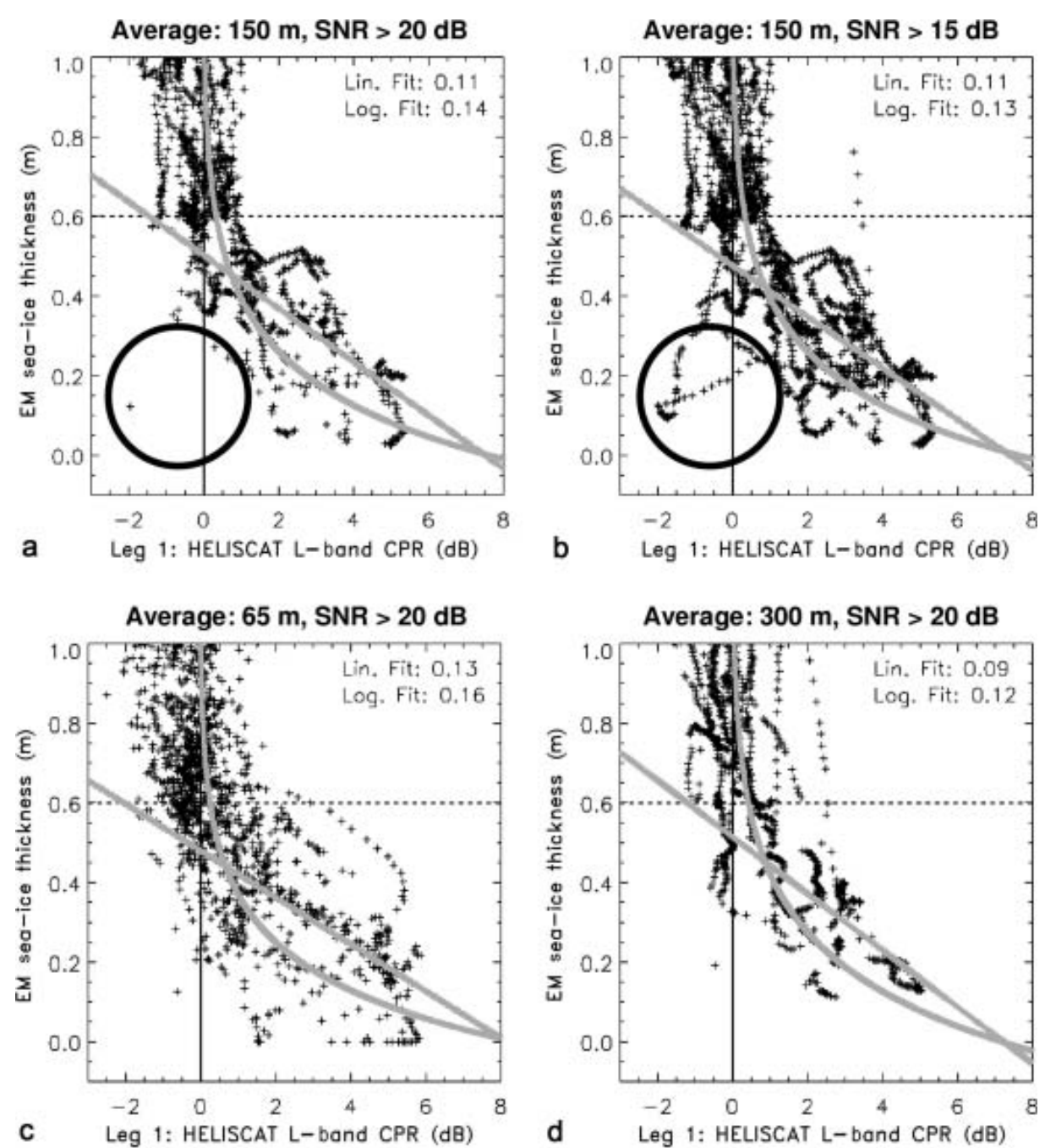

Fig. 2. EM ice thickness vs HELISCAT L-band CPR along leg 1 (see Fig. 1b) for different SNR values (only HELISCAT data) and averaging windows (both datasets). (a) SNR $>20 \mathrm{~dB}$, with $150 \mathrm{~m}$ averaging; (b) SNR $>15 \mathrm{~dB}$, with $150 \mathrm{~m}$ averaging; (c) SNR $>20 \mathrm{~dB}$, with $65 \mathrm{~m}$ averaging; and (d) SNR $>20 \mathrm{~dB}$, with $300 \mathrm{~m}$ averaging. Superposed are curves of a linear and a logarithmic fit. The rms differences (in metres) between the measured ice thickness and that estimated with the two fits are given in the upper right corner of each panel.

with the measured ice-thickness variability for the logarithmic fit. Because of this and because the achieved intercepts are substantially lower (cf., e.g., Fig. 3a and b), we suggest using the logarithmic fit. This agrees with earlier findings about the relationship between the CPR and the thickness of thin ice (e.g. Onstott, 1992; Wakabayashi and others, 2004).

The maximum obtainable thickness is around $50-60 \mathrm{~cm}$, which agrees to some extent with the findings of Wakabayashi and others (2004; see fig. 11b). They used an airborne fully polarimetric L-band synthetic aperture radar (Pi-SAR; spatial resolution $3 \mathrm{~m}$ ) to observe sea-ice radar backscatter in the Sea of Okhotsk just north of Hokkaido, Japan. The CPR at L-band (calculated from the scattering matrix) was averaged over $20 \mathrm{~m} \times 20 \mathrm{~m}$ gridcells with $10 \mathrm{~m}$ sampling distance along a track given by ice draft and drift observations made by moored sonar. These draft measurements were combined with the CPR observations (time difference $<10$ hours), both averaged along $100 \mathrm{~m}$ intervals, in order to obtain the empirical fit used to map the ice thickness from Pi-SAR CPR observations (Wakabayashi and others, 2004). The main difference between their approach and ours, regarding instrumentation, is that we benefit from quasisimultaneous (within seconds) measurements of ice thickness and radar backscatter along the same flight track.

A wider averaging window seems to improve our method (Table 1, bottom two rows). But the width of this window together with the footprint size (a few tens of metres for both sensors) determines the minimum observable size of the thin-ice areas: the larger the averaging window, the larger the required along-track extent of a thin-ice area. Moreover, the width of the averaging window influences the smallest observable thin-ice thickness and thereby the empirical fit, because open-water areas only a few tens of metres wide are smoothed out. The minimum observable ice thickness increases with the window width: $0 \mathrm{~cm}$ for $65 \mathrm{~m}, 2 \mathrm{~cm}$ for $150 \mathrm{~m}$ and $10 \mathrm{~cm}$ for $300 \mathrm{~m}$ (Fig. 2c, a and d). This would favour the use of a small averaging window. However, in order to sufficiently reduce instrument noise and noise inherent in the measurements due to small-scale sea-ice heterogeneities, the minimum size of the thin-ice areas to be observed should exceed two to three times the footprint size, i.e. at least $60-120 \mathrm{~m}$ Therefore, we regard the averaging window of $150 \mathrm{~m}$ as a good compromise. 

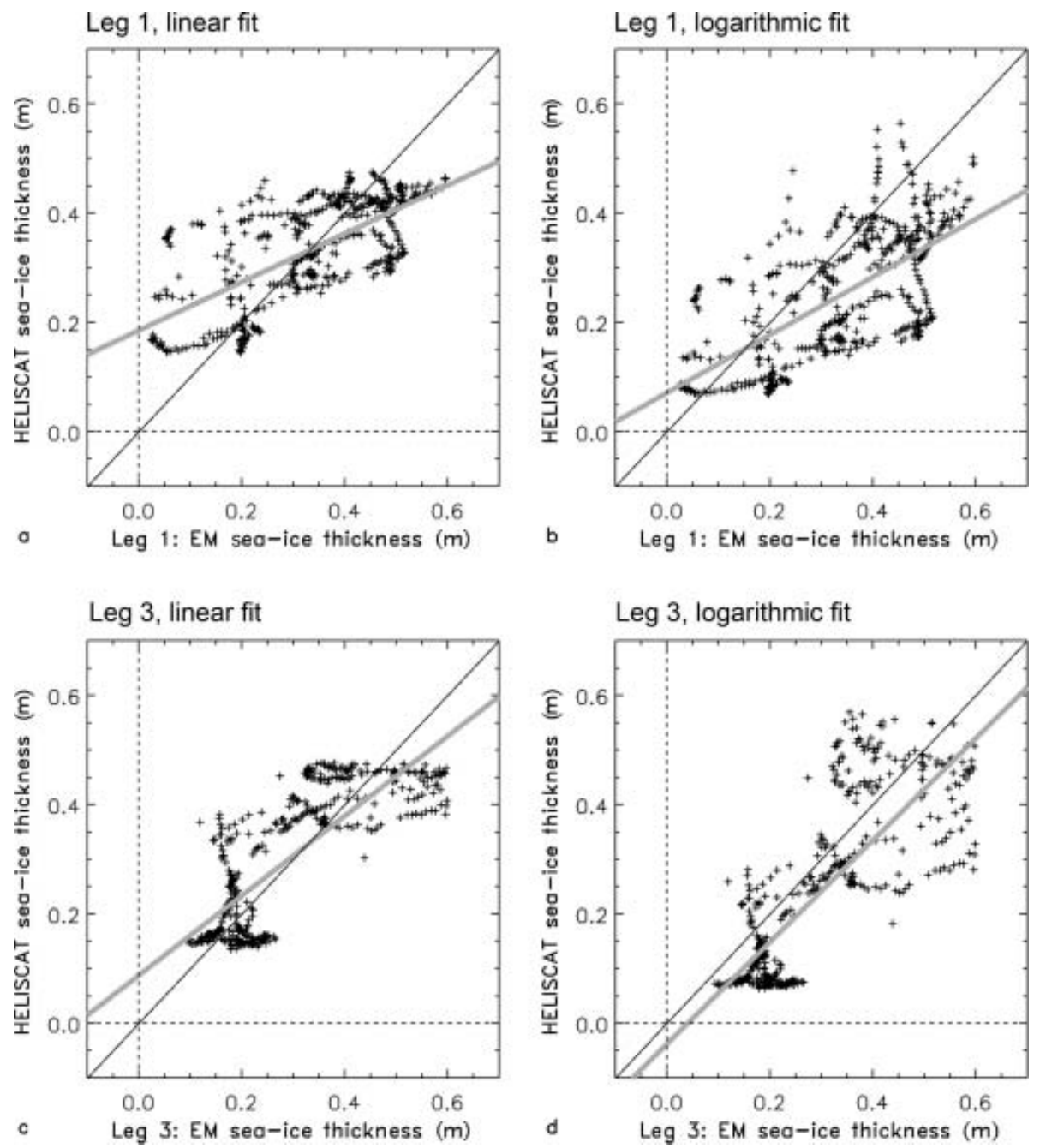

Fig. 3. HELISCAT-derived vs EM ice thickness using the fits obtained from data of leg 1 using $\mathrm{SNR}>20 \mathrm{~dB}$, with an averaging window of $150 \mathrm{~m}$ (plotted in Fig. 2a). Thicknesses are (a) for leg 1 using the linear fit; (b) for leg 1 using the logarithmic fit; and (c, d) for the independent data of leg 3 using the linear (c) and the logarithmic fit (d). Thick grey lines denote the linear regression between each of the thickness datasets shown; results of these regressions are also given in the two upper lines of Table 1. Thin black diagonals denote perfect agreement. Note the different vertical scale compared to Figure 2.

The HELISCAT measurements were carried out at $40^{\circ}$ incidence angle. Owing to the fact that the CPR change per unit change in thin-ice thickness $(1 \mathrm{~cm})$ is larger at higher incidence angles than at low ones (see section 3), our approach could benefit from radar backscatter measurements carried out at larger incidence angles. However, an important drawback of larger incidence angles is that the radar backscatter of level surfaces is closer to the noise level compared to smaller incidence angles. Another improvement would be to improve the accuracy of the independent ice-thickness measurements, particularly for very thin ice, for which the accuracy of the EM measurements decreases. Such an improvement could be to additionally calculate the thinice thickness via the heat-flux method (Drucker and others, 2003) using simultaneous IR temperature measurements.

Kwok and others (1995) noted that a highly saline brine skim could be present, particularly on very thin ice (below $10 \mathrm{~cm}$ ). Such a skim is responsible for the high copolarization values observed here. However, when the thin ice becomes covered even with a thin snow layer, this skim will vanish, the co-polarization ratio will decrease and the thin-ice thickness will be overestimated. A natural step to avoid this error source using our data would be to include the simultaneous video imagery in the analysis by classifying the thin ice into bare and snow-/slush-covered and develop the approach separately for different thin-ice classes.

\section{CONCLUSIONS}

The relationship between sea-ice thickness and likepolarized L-band radar backscatter has been investigated by synchronous helicopter-based measurements carried out north of Svalbard in April 2003, during a tandem flight of an EM induction ice-thickness sounder (EM-Bird) and a multifrequency, multi-polarization scatterometer (HELISCAT). These are combined to derive a method for thin-ice thickness solely from L-band CPR data. Co-located EM ice-thickness and HELISCAT L-band CPR data are compared after smoothing with a running mean of different length along track. A linear and a logarithmic fit are applied to the data for EM ice-thickness values between 0.0 and $0.6 \mathrm{~m}$ and 0.0 and $1.0 \mathrm{~m}$, respectively. The thin-ice thickness is derived by applying these fits to dependent (i.e. used to obtain the fits) and independent HELISCAT L-band CPR data. Subsequently, 
Table 1. Comparison between HELISCAT-derived and EM thin-ice thickness for ice-thickness values between 0.0 and $0.6 \mathrm{~m}$ Given are the leg numbers, the type of fit, the correlation between derived and measured thickness, the number of data pairs, the rms difference and intercept for the regression between the derived and measured thickness, and the standard deviation (STDV) of the mean derived and mean measured thickness within the above-given thickness limits. Top two lines: results for leg 1 (see Fig. 3a and b) and for leg 3 (see Fig. 3c and d); bottom two lines: mean results (except number of data pairs) considering all legs (dependent and independent data) for two different averaging windows

\begin{tabular}{|c|c|c|c|c|c|c|c|c|}
\hline \multirow{2}{*}{$\begin{array}{l}\text { Averaging } \\
\text { window }\end{array}$} & \multirow[t]{2}{*}{ Leg } & \multirow[t]{2}{*}{ Type of fit } & \multirow[t]{2}{*}{ Correlation } & \multirow{2}{*}{$\begin{array}{c}\text { Number of } \\
\text { data pairs }\end{array}$} & \multirow[t]{2}{*}{ rms difference } & \multirow[t]{2}{*}{ Intercept } & \multicolumn{2}{|c|}{ STDV of mean thickness } \\
\hline & & & & & & & Derived & Measured \\
\hline $\mathrm{m}$ & & & & & $\mathrm{m}$ & $\mathrm{m}$ & $\mathrm{m}$ & $\mathrm{m}$ \\
\hline 150 & 1 & Lin./log. & $0.673 / 0.646$ & $500 / 500$ & $0.07 / 0.09$ & $0.19 / 0.07$ & $0.09 / 0.12$ & $0.14 / 0.14$ \\
\hline 150 & 3 & Lin./log. & $0.798 / 0.800$ & $450 / 450$ & $0.08 / 0.10$ & $0.09 /-0.04$ & $0.12 / 0.16$ & $0.14 / 0.14$ \\
\hline 150 & $1,2,3$ & Lin./log. & $0.724 / 0.723$ & $1729 / 1729$ & $0.07 / 0.08$ & $0.17 / 0.06$ & $0.10 / 0.13$ & $0.13 / 0.13$ \\
\hline 300 & $1,2,3$ & Lin./log. & $0.800 / 0.811$ & $1700 / 1659$ & $0.05 / 0.07$ & $0.17 / 0.03$ & $0.10 / 0.13$ & $0.14 / 0.13$ \\
\hline
\end{tabular}

HELISCAT-derived and EM ice thickness are compared for ice-thickness values between 0.0 and $0.6 \mathrm{~m}$ using a linear regression. The logarithmic fit gave the most reliable results: correlation 0.72 ; intercept of regression $6 \mathrm{~cm}$; and $\mathrm{rms}$ difference $8 \mathrm{~cm}$. It has to be stressed here, however, that the approach can only be applied to thin ice, i.e. below 50$60 \mathrm{~cm}$ thickness, and that the role snow and/or slush has on the retrieval needs still to be investigated. Consequently, the next step is to apply the method to data of other HELISCAT flights carried out during ARK XIX/1 to further test the method, particularly with regard to the presence of snow or frost flowers on the surface because both can change the dielectric properties and roughness of the ice surface. The launch of ALOS-PALSAR (Advanced Land Observing Satellite-Phased Array-type L-band SAR) in early 2006 will provide space-borne L-band data to which our method could be applied after some modification, provided that the CPR will be available from these data and that requirements regarding SNR and incidence angle will be met. This might open the opportunity to obtain estimates of the thin-ice thickness on a regular basis independent of weather, daylight and limitations of numerical models.

\section{ACKNOWLEDGEMENTS}

This work was supported by the German Science Foundation (DFG): Me-487/40-1, SFB 512 - E1, and the European Union via EVG1-CT-2000-00029 (MARSAIS) and EVK2-CT-200200146 (SITHOS). We thank the crew of the R/V Polarstern, the helicopter team and J. Lieser, S. Willmes and T. Martin, as well as three anonymous reviewers.

\section{REFERENCES}

Arctic Climate Impact Assessment (ACIA). 2004. Impacts of a warming Arctic: Arctic Climate Impact Assessment. Cambridge, etc., Cambridge University Press.

Dierking, W., H. Skriver and P. Gudmandsen. 2003. On the improvement of sea ice classification by means of radar polarimetry. In Proceedings of the Workshop on SAR Polarimetry for Sea Ice Classification. Frascati, European Space Agency. European Space Research Institute. (ESA Special Publication SP-529.)

Drucker, R., S. Martin and R. Moritz. 2003. Observations of ice thickness and frazil ice in the St. Lawrence Island polynya from satellite imagery, upward looking sonar, and salinity/temperature moorings. J. Geophys. Res., 108(C5), 3149. (10.1029/ 2001JC001213.)

Haas, C. 2004. Late-summer sea ice thickness variability in the Arctic Transpolar Drift 1991-2001 derived from ground-based electromagnetic sounding. Geophys. Res. Lett., 31(9), L09402. (10.1029/2003GL019394.)

Kwok, R., S.V. Nghiem, S.H. Yueh and D.D. Huynh. 1995. Retrieval of thin ice thickness from multifrequency polarimetric SAR data. Remote Sens. Environ., 51(3), 361-374.

Kwok, R., H.J. Zwally and D. Yi. 2004. ICESat observations of Arctic sea ice: a first look. Geophys. Res. Lett., 31(16), L16401. (10.1029/2004GL020309.)

Laxon, S., N. Peacock and D. Smith. 2003. High interannual variability in sea ice thickness in the Arctic region. Nature, 425(6961), 947-950.

Nghiem, S.V. and 6 others. 1997. Evolution in polarimetric signatures of thin saline ice under constant growth. Radio Sci., 32(1), 127-152.

Onstott, R. 1992. SAR and scatterometer signatures of sea ice. In Carsey, F.D. and 7 others, eds. Microwave remote sensing of sea ice. Washington, DC, American Geophysical Union, 73-104. (Geophysical Monograph Series 68.)

Pfaffling, A., C. Haas and J.E. Reid. 2004. Empirical inversion of HEM data for sea ice thickness mapping. In Extended abstracts, 10th European Meeting of Environmental and Engineering Geophysics (EAGE's Near Surface 2004). [Abstract A037.] Utrecht, EAGE.

Reid, J., A. Pfaffling and J. Vrbancich. 2006. Airborne electromagnetic footprints in one-dimensional earths. Geophysics, 71(2), 63-72.

Rignot, E. and M.R. Drinkwater. 1994. Winter sea-ice mapping from multi-parameter synthetic-aperture radar data. J. Glaciol., 40(134), 31-45.

Rothrock, D.A., J. Zhang and Y. Yu. 2003. The Arctic ice thickness anomaly of the 1990s: a consistent view from observations and models. J. Geophys. Res., 108(C3), 3803. (10.1029/ 2001JC001208.)

Schauer, U. and G. Kattner. 2004. The expedition ARKTIS XIX/1 a, b and XIX/2 of the Research Vessel POLARSTERN in 2003. Rep. Polar Res. 481.

Wakabayashi, H., T. Matsuoka, K. Nakamura and F. Nishio. 2004. Polarimetric characteristics of sea ice in the Sea of Okhotsk observed by airborne L-band SAR. IEEE Trans. Geosci. Remote Sens., 42(11), 2412-2425.

Wismann, V., M. Gade, W. Alpers and H. Huhnerfuss. 1998. Radar signatures of marine mineral oil spills measured by an airborne multi-frequency radar. Int. J. Remote Sensing, 19(18), $3607-3623$. 